\title{
Boosting the Stability of Boron Peroxides through Subphthalocyanine Coordination
}

\author{
Jorge Labella ${ }^{a}$ \\ Elisa López-Serrano ${ }^{a}$ \\ Tomás Torres*a,b,c (i) \\ a Department of Organic Chemistry, Universidad Autónoma de Madrid, Campus de \\ Cantoblanco, 28049, Madrid, Spain \\ ${ }^{\mathrm{b}}$ Institute of Advanced Research in Chemical Sciences, Universidad Autónoma de \\ Madrid. Campus de Cantoblanco, 28049, Madrid, Spain \\ 'IMDEA-Nanociencia, C/ Faraday 9, Campus de Cantoblanco, 28049, Madrid, Spain \\ tomas.torres@uam.es \\ Dedicated to Professor Peter Bäuerle on the occasion of his 65th Anniversary.
}

Received: 3.02.2021

Accepted after revision: 24.02.2021

DOI: 10.1055/s-0041-1727093; Art ID: om-21-0019sc

License terms: CC $(\$$

(C) 2021. The Author(s). This is an open access article published by Thieme under the terms of the Creative Commons Attribution-NonDerivative-NonCommercial License, permitting copying and reproduction so long as the original work is given appropriate credit. Contents may not be used for commercial purposes, or adapted, remixed, transformed or built upon. (https://creativecommons.org/licenses/by-nc-nd/4.0/)

Abstract The great potential of subphthalocyanines (SubPcs) to stabilize boron peroxides has been demonstrated. In particular, a subphthalocyanato boron (III) peroxide has been prepared in good yield via boron triflate. This derivative is remarkably stable under ambient conditions and can be fully characterized. The impact of the peroxide group on the structural and optoelectronic properties of SubPc was examined by NMR and UV/Vis spectroscopies, as well as single-crystal Xray diffraction analysis. Moreover, density functional theory calculations were performed to explain the experimental results. The reactivity of this peculiar boron peroxide as an oxidant and a Lewis base was also studied.

Key words subphthalocyanines, phthalocyanine analogues, boron peroxides, porphyrinoids, macrocyclic ligands

\section{Introduction}

Since the discovery of Brown hydroboration-oxidation in the late $1950 \mathrm{~s},{ }^{1}$ organic boron peroxides have been of paramount importance in chemistry due to their remarkable versatility. For instance, these species have been widely used as initiators of radical chain reactions ${ }^{2}$ and postulated as key intermediates in many relevant transformations, such as oxygen activation, ${ }^{3}$ oxygen-transfer reactions ${ }^{4}$ or the palladium-catalyzed homocoupling of aryl boronic acids. ${ }^{5}$ However, despite extensive research in the field, there is still limited knowledge about the structural/electronic factors that govern
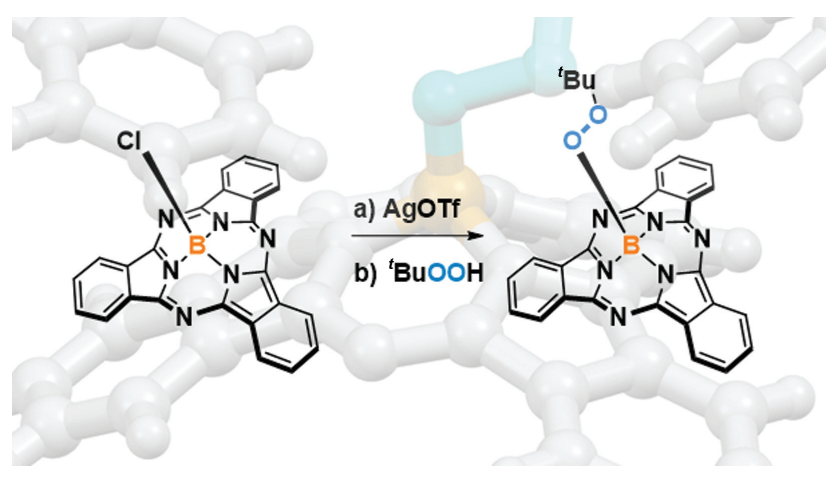

their stability and reactivity. This is primarily because boron peroxides typically show low stability and hence their full characterization is often hampered. Therefore, establishing new guidelines for the preparation of highly stable boron peroxides is crucial for their understating and further development.

To the best of our knowledge, there are only seven examples that report structurally characterized organic boron peroxides. $^{3 a, 3 b, 3 c, 6}$ In six of them, the strategy to stabilize the peroxide has involved its embedding in cyclic structures or its trapping with bulky electrophilic boranes. Nevertheless, although appealing, these systems are very particular and are not suitable for systematic studies. On the other hand, Osuka et al. demonstrated that the coordination of boron with subporphyrins (SubPs) significantly improves the stability (ROO-SubP, Figure 1). ${ }^{7}$ Indeed, this method allowed for the first time the characterization of acyclic and neutral boron peroxides. However, some of these peroxo-SubP still suffered from low stability under certain conditions, such a heating or reductive/electrophilic environments. In view of this precedent, one could think that the use of other subporphyrinic ligands may further improve such stability.

Related to SubP, subphthalocyanines (SubPcs) are an important class of porphyrinoids composed of an isoindolebased tridentate ligand that coordinates a central boron atom with an axial substituent. ${ }^{8}$ In contrast to SubP, SubPcs present peripheral benzene rings and nitrogen at peripheral and meso-positions, respectively. This structural difference
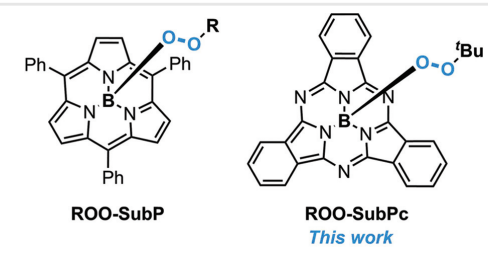

Figure 1 Molecular structure of SubP and SubPc boron peroxides. 
results in a more electrophilic boron atom that binds the axial substituent more strongly than SubP, particularly in the case of hard bases such as oxygen or fluorine. For this reason, the axial functionalization of SubPc with phenols or carboxylic acids has been the strategy of reference to prepare a variety of robust multicomponent systems. ${ }^{9}$ Taking this axial stability into account, we believed that SubPcs could also be a great candidate to prepare highly stable boron peroxides.

In this communication we disclose, for the first time, the synthesis and characterization of a boron (III) subphthalocyanato peroxide ( $\left.{ }^{\boldsymbol{}} \mathbf{B u O O}-\mathbf{S u b} \mathbf{P} \mathbf{C H} \mathbf{H}_{\mathbf{1 2}}\right)$. This derivative exhibits an outstanding stability under ambient conditions, which allows its full characterization both in solution and in solid state. X-Ray diffraction analysis reveals that the peroxide group is strongly bound to the boron atom and largely affects the organization within the crystal structure. On the other hand, relevant differences in the optical and electrochemical properties are also observed. The electronic structure of this derivative is also analyzed by density functional theory (DFT) calculations. Finally, the reactivity of this particular SubPc is briefly examined by carrying out its reaction with a reductant and a peroxide scavenger.

\section{Results and Discussion}

Non-substituted SubPc with tert-butyl-peroxide as the axial ligand was selected as a model substrate for this study ( ${ }^{\boldsymbol{B}} \mathbf{B u O O}-\mathbf{S u b P c H}_{\mathbf{1 2}}$, Scheme 1). The synthesis of ${ }^{{ } \mathbf{B u O 0} \text {-SubPcH }} \mathbf{1 2}_{2}$ was firstly tackled following various literature methods for the axial exchange of $\mathbf{C l}-\mathbf{S u b P c H}_{\mathbf{1 2}}$, such as the direct substitution in high boiling-point solvents or the use of trimethylsilyl nucleophiles. ${ }^{10}$ Moreover, the conditions used by Osuka et al. to prepare ROO-SubP were also tested. ${ }^{7}$ However, these attempts ended in recovery of $\mathbf{C l}-\mathrm{SubPcH}_{12}$ or macrocycle decomposition. Given this lack of reactivity of boron, we decided to employ triflate SubPc (TfO-SubPcH $\mathbf{1 2}_{\mathbf{1 2}}$ ). This activated intermediate was obtained following a procedure reported in our group, which involves the chlorine abstraction by silver triflate (AgOTf) ${ }^{11}$ Fortu-

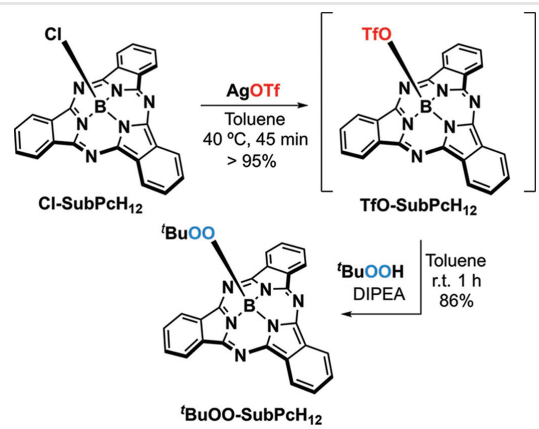

Scheme 1 Synthesis of ${ }^{t}$ BuOO-SubPcH ${ }_{12}$ through the activated intermediate TfO-SubPcH $_{12}$. nately, the subsequent one-pot reaction of $\mathbf{T f O}-\mathbf{S u b P c H}_{\mathbf{1 2}}$ with ${ }^{t} \mathrm{BuOOH}$ in the presence of diisopropylethylamine furnished ${ }^{{ }} \mathbf{B u O O} \mathbf{S u b P c H}_{\mathbf{1 2}}$ in $86 \%$ yield (Scheme 1). Remarkably, ${ }^{\boldsymbol{t}} \mathbf{B u O O} \mathbf{O} \mathbf{S u b P c H}_{\mathbf{1 2}}$ displayed an exceptional stability under ambient conditions, remaining unaltered after prolonged durations in solution, upon heating or even light exposures. Once isolated, this peroxide can be stored for several months without decomposition.

As a result of this stability, the full characterization of peroxide ${ }^{\boldsymbol{t}} \mathbf{B u O O}-\mathbf{S u b P c H}_{\mathbf{1 2}}$ was readily accomplished by several spectrometric and spectroscopic techniques (see the Supporting Information). The parent ion peak of

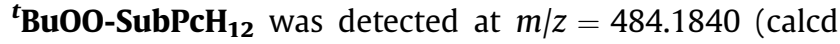
for $\left.\left(\mathrm{C}_{28} \mathrm{H}_{21} \mathrm{BN}_{6} \mathrm{O}_{2}\right)^{+}=484.1819[\mathrm{M}]^{+}\right)$by matrix-assisted laser desorption ionization time-of-flight (MALDI-TOF) mass spectrometry. Additionally, other characteristic signals such as the loss of axial substituent or SubPc with a hydroxy ligand were also observed. The ${ }^{1} \mathrm{H}$ NMR spectrum is quite simple, exhibiting the $\mathrm{AA}^{\prime} \mathrm{XX}^{\prime}$ system of perhydrogenated SubPc with a $C_{3 v}$ symmetry ( $\alpha$-protons at $8.88 \mathrm{ppm}$ and $\beta$-protons at $7.89 \mathrm{ppm}$ ), and a singlet at $0.34 \mathrm{ppm}$ corresponding to tert-butyl moiety. On the other hand, the ${ }^{11} \mathrm{~B}-\mathrm{NMR}$ displays a sharp singlet at $-13.8 \mathrm{ppm}$. As observed for ${ }^{\boldsymbol{t}} \mathbf{B u O}$-SubP, SubPc with tert-butoxy at the axial position $\left({ }^{\mathbf{t}} \mathbf{B u O}-\mathbf{S u b P C H}_{\mathbf{1 2}}\right)^{\mathbf{1 1}}$ exhibits all of these spectral signals at lower frequencies, ${ }^{12}$ suggesting that the peroxo ligand is more electron withdrawing than tertbutoxy.

Single crystals of ${ }^{\boldsymbol{t}} \mathbf{B u O 0}-\mathbf{S u b P c H}_{\mathbf{1 2}}$ suitable for X-ray diffraction analysis were obtained by slow diffusion of methanol into its chloroform solution. The structure of ${ }^{\boldsymbol{t}} \mathbf{B u O O} \mathbf{S u b P c H} \mathbf{H}_{12}$ and selected crystallographic data are shown in Figure 2a and Table 1, respectively. Compared to ${ }^{\boldsymbol{t}} \mathbf{B u O}$-SubP, ${ }^{\boldsymbol{t}} \mathbf{B u O O}-\mathbf{S u b P c H}_{\mathbf{1 2}}$ exhibits a very similar O-O bond length (1.480 $\AA$ and $1.475 \AA$ ). In contrast, they differ significantly in B-O bond lengths (1.445 $\AA$ and $1.450 \AA$ ), being shorter in the latter case. This fact suggests that tert-butyl-peroxide is linked to the boron atom much
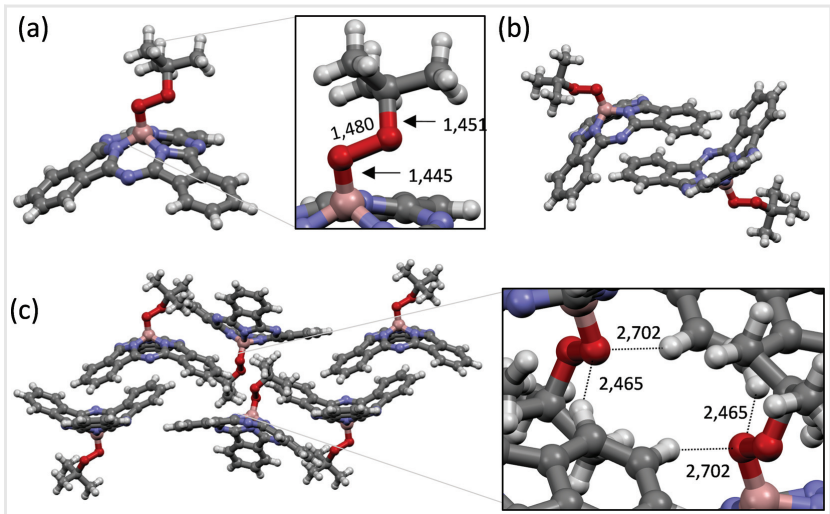

Figure 2 (a) X-Ray structure, (b) concave-concave head-to-tail dimers and (c) crystalline packing of ${ }^{t} \mathbf{B u O O}-\mathbf{S u b P c H}_{12}$. 
Table 1 Bod lengths $(\AA)$ and bowl depths (BDs) ${ }^{a}$

\begin{tabular}{llllll}
\hline Compound & $\mathrm{O}-\mathrm{O}$ & $\mathrm{B}-\mathrm{O}$ & $\mathrm{BD}_{\text {pyr }}$ & $\mathrm{BD}_{\text {imine }}$ & $\mathrm{BD}_{\text {term }}$ \\
\hline${ }^{{ }^{B}{ }_{\text {Bu-OOSubPcH }}{ }_{\mathbf{1 2}}}$ & 1.480 & 1.445 & 0.601 & 1.171 & 2.575 \\
${ }^{{ }{ }_{\text {BuO-SubPCH }}{ }_{12}}$ & - & 1.406 & 0.656 & 1.221 & 2.702 \\
CH $_{\mathbf{3}}$ COO-SubPcH $_{12}$ & - & 1.462 & 0.609 & 1.184 & 2.534 \\
${ }^{{ }_{\text {BuO-SubP }}}$ & 1.475 & 1.457 & 0.586 & - & - \\
\hline
\end{tabular}

${ }^{\mathrm{a} B o w l}$ depth is defined as the distance between the boron atom and the plane containing: the pyrrolic nitrogen $\left(\mathrm{BD}_{\mathrm{pyr}}\right)$, the meso nitrogen $\left(\mathrm{BD}_{\text {imine }}\right)$ or the outermost carbon atoms $\left(\mathrm{BD}_{\text {term }}\right)$.

stronger in SubPc than SubP. On the other hand, when compared to other SubPcs with B-O bonds, as ${ }^{{ } \mathbf{B u O}^{-S u b P c H}}{ }_{12}$ and $\mathbf{C H}_{3} \mathbf{C O O}-\mathbf{S u b P c H}_{12}$ (acetate-), ${ }^{\boldsymbol{t}_{\mathrm{BuO0}-S u b P c H}} \mathbf{1 2}_{\mathbf{1 2}}$ exhibits a relatively long $\mathrm{B}-\mathrm{O}$ bond that resembles that of a SubPc bearing an axial carboxylate. Accordingly, the bowl-shape structure of ${ }^{\boldsymbol{t}} \mathbf{B u O O}-\mathbf{S u b P c H}_{\mathbf{1 2}}$ is flatter than that of ${ }^{\boldsymbol{t}} \mathbf{B u O}-\mathbf{S u b P c H} \mathbf{H}_{\mathbf{1 2}}$ and similar to that of $\mathbf{C H}_{\mathbf{3}} \mathbf{C O O}-\mathbf{S u b P C H}_{\mathbf{1 2}}$, as inferred from bowl depth values. Thus, although more stable than SubP, it can be expected that axial peroxide SubPc could be a good leaving group rendering SubPc peroxides interesting precursors to generate cationic SubPc-based boron species. ${ }^{13}$ With regard to the crystal packing, ${ }^{\boldsymbol{t}} \mathbf{B u O 0}$-SubPcH $\mathbf{P H}_{\mathbf{1 2}}$ arranges in a monoclinic crystal with a $P 121 / n 1$ space group. Each molecule is organized in concave-concave head-to-head dimers linked together by $\pi-\pi$ interactions $(c v-c v h-h$; Figure $2 \mathrm{~b}) .{ }^{14}$ These dimers, in turn, interact with adjacent dimers through $\mathrm{O} \cdots \mathrm{H}$ (2.465-2.702 $\AA$ ) giving rise to the solid-state packing depicted in Figure $2 c$.

Concerning the optoelectronic properties, ${ }^{\boldsymbol{t}} \mathbf{B u O 0}-$ SubPcH $_{12}$ displays the typical UV/Vis absorption and emission spectra of a SubPc derivative (Figure 3a), comprising a Soret band at $305 \mathrm{~nm}$ and a Q-band at $563 \mathrm{~nm}$, and a fluorescence maximum at $580 \mathrm{~nm}$. More interestingly, it was found that the peroxo ligand enhanced the quantum yield (0.86) in comparison with the starting $\mathbf{C l - S u b P c H} \mathbf{H}_{\mathbf{1 2}}$ $(0.73) .{ }^{15}$ Subsequently, the electrochemical behaviour of this unique derivative was examined by cyclic and differential pulse voltammetry (Figure 3b). The first reduction and oxidation peaks appear within the expected range of unsubstituted SubPcs and correspond to oneelectron processes. ${ }^{16}$ However, to our surprise, while the first reduction is reversible in $\mathbf{C l}-\mathbf{S u b P c H} \mathbf{P H}_{\mathbf{1 2}}$, in the case of ${ }^{\boldsymbol{t}} \mathbf{B u 0 0 - S u b P c H} \mathbf{1 2}_{\mathbf{1 2}}$ this process was found to be irreversible, suggesting that the radical anion of SubPc is not so stable with peroxide as an axial substituent.

In order to gain further insights into the electronic structure of ${ }^{\boldsymbol{t}} \mathbf{B u O O}-\mathbf{S u b P c H}_{\mathbf{1 2}}$, we performed DFT and timedependent-DFT calculations at the CAM-B3LYP/6-31G(d) level of theory (Figure $3 \mathrm{c}$ ). In line with the experimental results, the simulated UV/Vis spectrum comprises two intense absorption bands ( $\mathrm{Q}$ and Soret) which correspond to the HOMO-LUMO and HOMO-LUMO + 1 transitions

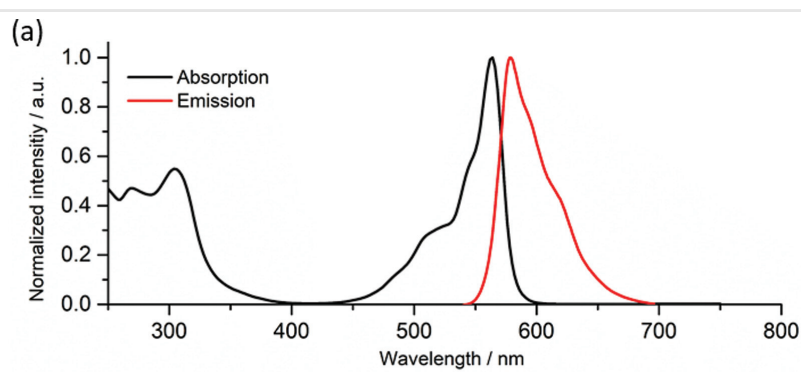

(b)

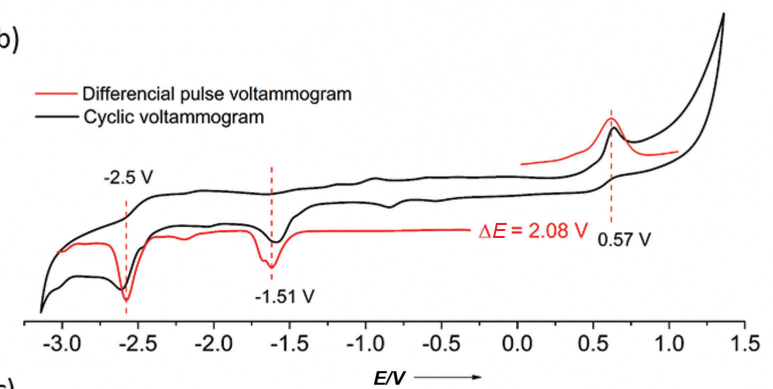

(c)

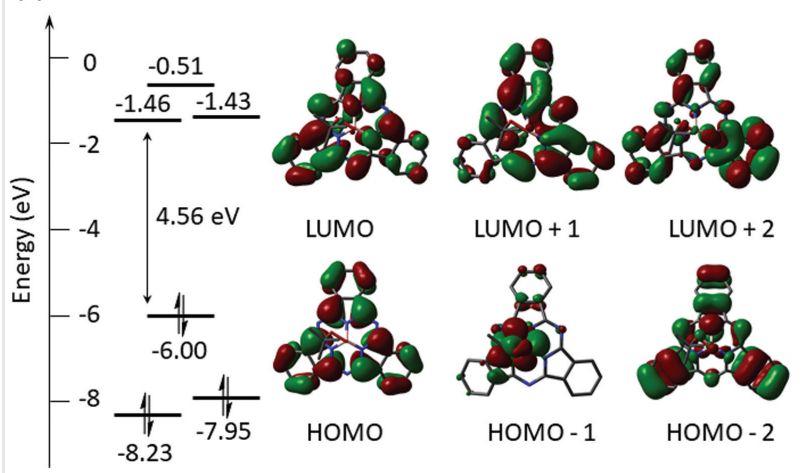

Figure 3 (a) UV/Vis absorption and emission spectra of ${ }^{{ }} \mathrm{BuOO}$ SubPcH $_{12}$ in toluene. (b) Cyclic voltammograms (black lines) and differential pulse voltammograms (red lines) of ${ }^{\mathbf{t}} \mathbf{B u O O}-\mathbf{S u b P c H}_{12}$ in THF ( $V$ vs. ferrocene/ferrocenium ion couple). Supporting electrolyte, $\mathrm{Bu}_{4} \mathrm{NPF}_{6}(0.10 \mathrm{M})$; working electrode, glassy carbon; counter electrode, platinum wire; reference electrode, $\mathrm{Ag} / \mathrm{AgNO}_{3}$. (c) Molecular orbital diagram of ${ }^{{ }}$BuOO-SubPcH ${ }_{12}$ calculated at the CAM-B3LYP/6-31G(d) level.

(oscillator strengths of 0.3354 and 0.3363 , respectively). The orbitals involved in such transition are mainly localized over the aromatic skeleton thus reaffirming that the axial ligand does not affect the optical properties of SubPcs. ${ }^{8}$ Accordingly, ${ }^{\mathbf{t}} \mathbf{B u O O}-\mathbf{S u b P c H}_{\mathbf{1 2}}$ and $\mathbf{C l}-\mathbf{S u b P c H}_{\mathbf{1 2}}$ displays similar UV/Vis profiles. In the case of the orbitals responsible for the electrochemical reduction (LUMOs), a certain contribution of the peroxo fragment is observed. However, it is negligible when compared to that of the p-skeleton and

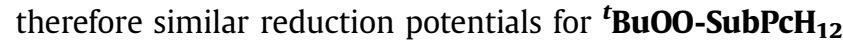
and $\mathbf{C l}-\mathbf{S u b P c H}_{12}$ are expected. On the other hand, the HOMO - 1, which is 1.95 e V more stable than the HOMO, is entirely located over the tert-butyl-peroxide ligand, particularly in the oxygen lone-pair region. This highly stable orbital 


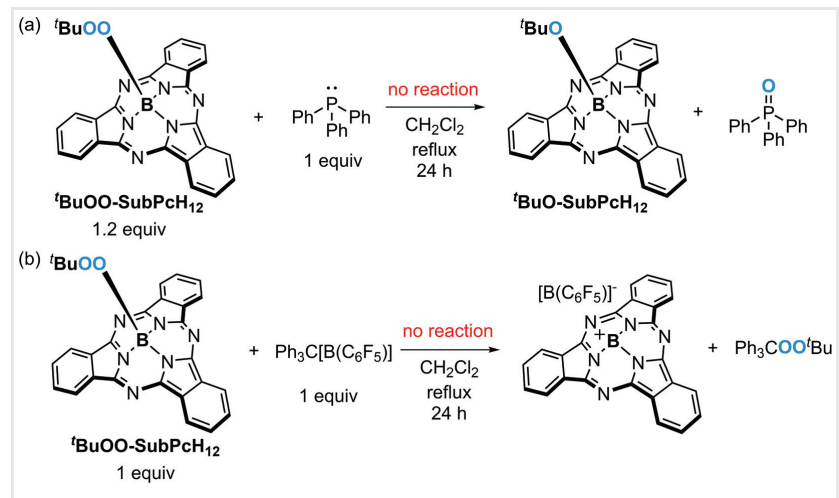

Scheme 2 Reactivity of ${ }^{\mathrm{t}} \mathrm{BuOO}-\mathrm{SubPcH}_{12}$. and should be considered for systematic studies. Apart from this, we believe that peroxo SubPcs could be key intermediates within the SubPc research, for instance in the discovery of novel axial reactions, the understanding of SubPc photooxidation in solar cells, or the therapy with several reactiveoxygen species.

\section{Funding Information}

Financial support from Spanish MINECO (CTQ201785393-P) is acknowledged. IMDEA Nanociencia acknowledges support from the "Severo Ochoa" Programme for Centres of Excellence in R\&D (MINECO, Grant SEV20160686).

\section{Acknowledgment}

${ }^{\boldsymbol{t}} \mathbf{B u O O} \mathbf{S u b P c H} \mathbf{H}_{\mathbf{1 2}}$ against electrophiles.

Finally, the reactivity of this peculiar SubPc was preliminarily explored (Scheme 2). To this end, we considered two kinds of reactions. First, we evaluated the oxidant properties of ${ }^{\boldsymbol{t}} \mathbf{B u O O}-\mathbf{S u b P C H}_{\mathbf{1 2}}$ by carrying out a reaction with triphenylphosphine as a reductant (Scheme 2a). To our surprise and, in contrast to peroxo-SubP, the disappearance of 3 was not observed even after 24 h at reflux. Then, in a second experiment, the reactivity of ${ }^{\boldsymbol{t}} \mathbf{B u O O}-\mathbf{S u b P c H}_{\mathbf{1 2}}$ as a nucleophile was tested by performing the reaction with trityl cation $\left(\mathrm{Ph}_{3} \mathrm{C}^{+}\right)$as a peroxide scavenger (Scheme $2 \mathrm{~b}$ ). Again,

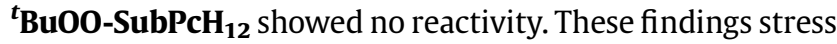
the higher stability of SubPc boron peroxide with respect to its SubP analogue.

\section{Conclusions}

In summary, we have described the synthesis of the first SubPc boron peroxide ( ${ }^{\boldsymbol{t}} \mathbf{B u O O}-\mathbf{S u b P c H} \mathbf{H}_{\mathbf{1 2}}$ ). This compound exhibits a remarkable stability both in solution and solid state, which has allowed its full characterization. In this regard, it has been found that the peroxyl moiety has a significant impact on the structural and electronic properties. For instance, the solid-state packing of ${ }^{\boldsymbol{t}} \mathbf{B u O O}-\mathbf{S u b P C H}_{\mathbf{1 2}}$ is governed by $\mathrm{O} \cdots \mathrm{H}$ interactions formed between the $\mathrm{O}-\mathrm{O}$ fragment and peripheral hydrogen atoms, and the fluorescence quantum yield is enhanced. On the other hand, the irreversible reductions observed by electrochemical measurements suggested that the peroxide ligand negatively affects the stability of the reduced SubPc. Finally, the reactivity as a mild oxidant and nucleophiles has been tested. In contrast to its SubP congener, which reacts at room temperature in few minutes, ${ }^{\boldsymbol{t}} \mathbf{B u O O}-\mathbf{S u b P C H} \mathbf{H}_{\mathbf{1 2}}$ has not shown activity when reacted with triphenylphosphine or trityl cation. For the above results, we can conclude that SubPc is an excellent ligand for the stabilization of boron peroxides
J.L. acknowledges MECD, Spain, for a F.P.U. fellowship. Generous allocation of computational time from the Centro de Computación Científica UAM is gratefully acknowledged.

\section{Supporting Information}

Supporting information for this article is available online at: https://doi.org/10.1055/s-0041-1727093.

\section{Primary Data}

The primary data generated during this study are available at: https://doi.org/10.1055/s-0041-1727093.

\section{References And Notes}

(1) Brown, H. C.; Zweifel, G. J. Am. Chem. Soc. 1959, 81, 247.

(2) Ollivier, C.; Renaud, P. Chem. Rev. 2001, 101, 3415.

(3) (a) Wood, T. K.; Piers, W. E.; Keay, B. A.; Parvez, M. Angew. Chem. Int. Ed. 2009, 48, 4009. (b) Henthorn, J. T.; Agapie, T. Angew. Chem. Int. Ed. 2014, 53, 12893. (c) Kong, L.; Lu, W.; Li, Y.; Ganguly, R.; Kinjo, R. Angew. Chem. Int. Ed. 2016, 55, 14718. (d) Tao, X.; Daniliuc, C. G.; Janka, O.; Poettgen, R.; Knitsch, R.; Hansen, M. R.; Eckert, H.; Luebbesmeyer, M.; Studer, A.; Kehr, G.; Erker, G. Angew. Chem. Int. Ed. 2017, 56, 16641.

(4) (a) Clay, J. M.; Vedejs, E. J. Am. Chem. Soc. 2005, 127, 5766. (b) Salomon, M. A.; Braun, T.; Penner, A. Angew. Chem. Int. Ed. 2008 47, 8867. (c) Baumgarth, H.; Meier, G.; von Hahmann, C. N.; Braun, T. Dalton Trans. 2018, 47, 16299.

(5) Adamo, C.; Amatore, C.; Ciofini, I.; Jutand, A.; Lakmini, H. J. Am. Chem. Soc. 2006, 128, 6829.

(6) (a) Porcel, S.; Bouhadir, G.; Saffon, N.; Maron, L.; Bourissou, D. Angew. Chem.Int.Ed. 2010,49, 6186. (b) Taylor,J.W.; McSkimming, A.; Guzman, C. F.; Harman, W. H.J. Am. Chem. Soc. 2017, 139, 11032. (c) Wang, B.; Kinjo, R. Chem. Sci. 2019, 10, 2088. 
(7) Tsurumaki, E.; Sung, J.; Kim, D.; Osuka, A. Angew. Chem. Int. Ed. 2016, 55, 2596.

(8) Claessens, C. G.; González-Rodríguez, D.; Rodríguez-Morgade, M. S.; Medina, A.; Torres, T. Chem. Rev. 2014, 114, 2192.

(9) See Section 2.5.6. of Ref. 8 and references therein. For examples on SubPc properties, see also:. (a) Claessens, C. G.; GonzalezRodriguez, D.; Torres, T.; Martin, G.; Agullo-Lopez, F.; Ledoux, I.; Zyss, J.; Ferro, V. R.; Garcia de la Vega, J. M. J. Phys. Chem. B. 2005, 109, 3800. (b) Verreet, B.; Rand, B. P.; Cheyns, D.; Hadipour, A.; Aernouts, T.; Heremans, P.; Medina, A.; Claessens, C. G.; Torres, T. Adv. Energy Mater. 2011, 1, 565. (c) Lavarda, G.; Zirzlmeier, J.; Gruber, M.; Rami, P. R.; Tykwinski, R. R.; Torres, T.; Guldi, D. M. Angew. Chem., Int. Ed. 2018, 57, 16291. (d) Zirzlmeier, J.; Lavarda, G.; Gotfredsen, H.; Papadopoulos, I.; Chen, L.; Clark, T.; Tykwinski, R. R.; Torres, T.; Guldi, D. M. Nanoscale 2020, 12, 23061. (b) Guilleme, J.; Martínez-Fernández, L.; Corral, I.; Yáñez, M.; González-Rodríguez, D.; Torres, T. Org. Lett. 2015, 17, 4722.

(11) Guilleme, J.; Gonzalez-Rodriguez, D.; Torres, T. Angew. Chem. Int. Ed. 2011, 50, 3506.

(12) Synthetic procedure for ${ }^{\boldsymbol{t}} \mathbf{B u O O} \mathbf{S u b P c H} \mathbf{H}_{\mathbf{1 2}}$ : In a $10 \mathrm{~mL}$ roundbottomed flask, equipped with a magnetic stirrer and a rubber seal, $\mathbf{C l}-\mathrm{SubPcH}_{12}(0.025 \mathrm{mmol})$ and silver trifluoromethanesulfonate $(0.031 \mathrm{mmol} ; 1.25$ equiv) were placed. Anhydrous toluene $(3 \mathrm{~mL})$ was added and the mixture was stirred under an argon atmosphere at room temperature until the disappearance of the SubPcCl starting material, which was monitored by TLC. At this point tert-butyl peroxide (5-6 $\mathrm{M}$ in decane, $0.031 \mathrm{mmol}$, 1.25 equiv) and $\mathrm{N}, \mathrm{N}$-diisopropylethylamine $(0.031 \mathrm{mmol}$, 1.25 equiv) were added. The reaction mixture was then stirred at $50{ }^{\circ} \mathrm{C}$ for $20 \mathrm{~min}$. The residue was purified by column chromatography on silica gel using toluene/AcOEt (5:1) as the eluent. The product obtained from the column was further purified washing with cold hexane. ${ }^{t} \mathbf{B u O O} \mathbf{S u b P c H} \mathbf{P H}_{12}$ was isolated as a pink solid in $86 \% .{ }^{\mathbf{1}} \mathbf{H}-\mathbf{N M R}\left(300 \mathrm{MHz}, \mathrm{CDCl}_{3}\right): \delta$ $\mathrm{ppm}=8.88(\mathrm{~m}, 6 \mathrm{H}), 7.89(\mathrm{~m}, 6 \mathrm{H}), 0.34(\mathrm{~s}, 9 \mathrm{H}) .{ }^{13} \mathrm{C}-\mathbf{N M R}$ $\left(75.5 \mathrm{MHz}, \mathrm{CDCl}_{3}\right): \delta \mathrm{ppm}=151.6,131.2,129.8,122.3,25.4$. ${ }^{11} \mathbf{B}-N M R\left(96 \mathrm{MHz}, \mathrm{CDCl}_{3}\right): \delta \mathrm{ppm}=-13.8$. HRLSI-MS (MALDITOF): Calculated for $\mathrm{C}_{28} \mathrm{H}_{21} \mathrm{BN}_{6} \mathrm{O}_{2}$ : 484.1819; Found: 484.1840 . UV/vis (DCM): $\lambda_{\max }(\mathrm{nm})(\log \varepsilon) ; \boldsymbol{\Phi}_{\mathbf{F}}($ exc. $\lambda=570 \mathrm{~nm})=0.86$; FT-IR: $v\left(\mathrm{~cm}^{-1}\right)=3062,2972,2913,1613,1453,1283,1128$, 1058, 744. Mp $>200{ }^{\circ} \mathrm{C}$

(13) Kato, T.; Tham, F. S.; Boyd, P. D. W.; Reed, C. A. Heteroat. Chem. 2006, 17, 209.

(14) To understand the notation of the different arrangements of SubPcs in the solid state, please see Section 2.4.1 of Ref 8.

(15) Fulford, M. V.; Jaidka, D.; Paton, A. S.; Morse, G. E.; Brisson, E. R. L.; Lough, A. J.; Bender, T. P. J. Chem. Eng. Data 2012, 57, 2756.

(16) Reduction between $-1.58 \mathrm{~V}$ and $-0.82 \mathrm{~V}$ and oxidation between $1.15 \mathrm{~V}$ and $0.37 \mathrm{~V}$. See Section 2.3.7 of Ref 8 for further details. 